\title{
Recomendaciones Rama de Dermatología Pediátrica, Sociedad Chilena de Pediatría. Pandemia COVID-19
}

\author{
Recommendations Pediatric Dermatology Branch, Chilean Society of Pediatrics. \\ COVID-19 pandemic
}

\author{
Ma. Angélica Macias E. ${ }^{a}$, Estela Zapata G. , Ma. Carolina González A. , Héctor Fuenzalida \\ Juan Honeyman ${ }^{\mathrm{a}}$, Francisco Chávez ${ }^{\mathrm{a}}$, Marco Chahuan ${ }^{\mathrm{a}}$, Héctor Córdova ${ }^{\mathrm{a}}$, Rodrigo Albornoz ${ }^{\mathrm{a}}$
}

aRama de Dermatología Pediátrica, Sociedad Chilena de Pediatría. Chile.

Recibido: 7 de mayo de 2020; aceptado: 18 de mayo 2020

\begin{abstract}
Resumen
La actual pandemia por Covid-19 (SARS-CoV-2) corresponde a una zoonosis viral altamente contagiosa que ha requerido extremar las medidas de protección personal con el fin de disminuir la transmisión del virus, tanto en ambientes hospitalarios como fuera de ellos, siendo necesaria la adopción de estrictos métodos de aislamiento tanto de contacto como aerosoles. Esto ha requerido la adopción de múltiples equipos de protección personal, dentro de los que se encuentran la protección ocular, mascarillas, escudo de protección facial, gorros, guantes, etcétera. Lo anterior ha generado un aumento en el daño de la barrera cutánea y, por lo tanto, la aparición de diversas dermatosis dentro de las que se encuentran dermatitis de contacto irritativa o alérgica, reacciones acneiformes, agravamiento de dermatosis previas, entre otras, cobrando así vital importancia el cuidado y restablecimiento de la barrera cutánea con medidas esenciales como aplicación de productos humectantes o emolientes y el correcto uso de los equipos en mención. No obstante, no solo se generan dermatosis derivadas del uso de equipos de protección personal, sino que también, dentro del amplio espectro de manifestaciones dermatológicas que puede generar la enfermedad por Covid-19 propiamente tal, incluyendo compromiso cutáneo, piloso (efluvio telógeno) o ungueal (onicomadesis). Por otro lado pero no motivo de este artículo, el compromiso cutáneo puede corresponder a la primera expresión clínica de la enfermedad o ser un predictor de su evolución. Dentro de lo anterior encontramos la urticaria aguda, exantema maculo-papular, exantema varicela-like, erupción petequial, perniosis-like y lívedo reticularis como las principales formas de afección cutánea hasta el momento.
\end{abstract}

Palabras clave:

Pandemia;

COVID-19;

Equipo de Protección

Personal;

Dermatología 


\section{Abstract}

The current Covid-19 pandemic (SARS-CoV-2) corresponds to a highly contagious viral zoonosis that has required to extreme measures in order to decrease the transmission of the virus in hospital settings and outside of them, requiring adoption of strict isolation methods, both contact and aerosols. This has required the adoption of multiple personal protective equipment, including eye protection, masks, face shield, medical caps, gloves, etc. The aforementioned has generated an increase in the damage of the skin barrier, and therefore, the appearance of various dermatoses, among which are irritative o alergic contact dermatitis, acneiform reactions, aggravation of previous dermatoses, and others, thus becoming vital protection and restoration of the skin barrier with measures such as the application of moisturizing or emollient products and the correct use of personal protection equipment. However, not only dermatoses are generated derived from the use of personal protection equipment, but also, within the wide spectrum of dermatological manifestations that Covid-19 disease itself can generate, including cutaneous, hairy involvement (telogen effluvium) or nail (onychomadesis). Cutaneous involvement may correspond to the first clinical expression of the disease or be a predictor of its evolution. Among the above we find acute urticaria, maculo-papular rash, chickenpox-like rash, petechial rash, perniosis-like, and livedo reticularis as the main forms of skin condition to date.

\section{Keywords:}

Pandemics;

COVID-19;

Personal Protective

Equipment;

Dermatology

\section{Introducción}

La pandemia actual denominada por la Organización Mundial de la Salud (OMS) "Enfermedad por Nuevo Coronavirus 2019 (SARS-2/COVID-19)" es una zoonosis viral altamente contagiosa que requiere extremar las medidas para mitigar la transmisión del virus en los ambientes hospitalarios, mediante protocolos estrictos de aislamiento de contacto y aerosoles que permitan resguardar al personal médico y paramédico, así como al resto de personal administrativo y asistencial, de dicho contagio.

Para esto es fundamental utilizar elementos de protección personal (EPP) de forma permanente, guardando ciertas medidas de seguridad que disminuyan el riesgo de contacto con el virus. Sin embargo, el uso prolongado y repetido de tales elementos también puede ocasionar problemas dermatológicos de distinto orden y gravedad.

La (OMS) estableció directrices estándar, las cuales incluyen el uso de:

- Protección ocular.

- Máscaras N95.

- Escudo protector facial.

- Gorros.

- Guantes.

- Batas o trajes especiales.

- Lavado frecuente de manos.

- Higienización de manos antes y después del contacto con pacientes.

Todos estos elementos de protección utilizados durante largas jornadas laborales, asociado a la higiene personal excesiva, pueden alterar la barrera cutánea y de las mucosas, causando lesiones por presión y fricción. El sitio que ha demostrado ser el más afectado es el puente nasal (debido al uso de gafas protectoras). Además, se han descrito:

- Dermatitis de contacto, prurito, urticaria por presión y exacerbación de procesos inflamatorios preexistentes, como dermatitis seborreica y acné.

- Hiperhidrosis, la cual al generar humedad predispone a maceración, y colonización bacteriana y micótica.

- Alteraciones en el pelo, entre ellas caída masiva de cabello (efluvio telógeno) y alopecia areata.

- Alteraciones en las uñas, que pueden sufrir alteraciones como fragilidad de las láminas, desprendimiento por capas (onicosquisis), cambios en el color, e incluso cambios peri ungueales, que son potenciales puertas de entrada a microorganismos, agravando así cuadros de paroniquia y dermatitis de las manos.

- Efectos del estrés sobre dermatosis previas: dermatosis inflamatorias crónicas como la dermatitis seborreica, la dermatitis atópica, la psoriasis, el vitiligo y el acné se suelen exacerbar ante condiciones de estrés.

- Afectación conjuntival, ya que el virus puede afectar las conjuntivas tarsal y bulbar, pudiendo generar procesos inflamatorios como conjuntivitis folicular y quemosis, la cual es indistinguible de otras conjuntivitis virales.

- Anosmia y disgeusia: cerca del $80 \%$ de los pacientes con infección por el SARS-CoV-2/COVID-19 sufren pérdida total del olfato, y el $88 \%$ tiene dificultades para identificar los sabores dulce, salado o amargo. 
Los signos clínicos más frecuentemente reportados por el personal de salud que trabaja en contacto con pacientes con coronavirus son eritema, pápulas, maceración y descamación, mientras que los síntomas más reportados corresponden a ardor, prurito y escozor. Estos signos y síntomas se presentan principalmente en cara y manos.

Por todo lo anterior desde la Rama de Dermatología de la SOCHIPE nos permitimos hacer las siguientes recomendaciones encaminadas a reducir el riesgo de lesiones cutáneas en el personal de la salud durante la presente pandemia, derivadas del uso de los implementos de protección personal, indispensables para la prevención del contagio con SARS-CoV-2/COVID-19.

Estas recomendaciones son de orientación general para la práctica clínica, y el personal de la salud las debe seguir de forma individualizada de acuerdo a sus necesidades y a los recursos disponibles:

\section{Recomendaciones generales para la higiene e hidratación de las manos y el rostro:}

\section{Higiene de manos}

- Lavado de manos y rostro: lávese las manos con agua y jabón. Se recomienda el lavado de manos durante al menos 20 segundos con jabones antisépticos o neutros. Las personas con factores de riesgo (antecedentes de dermatitis atópica, dermatitis de contacto $\mathrm{u}$ otros procesos inflamatorios de la piel) pueden utilizar surfactantes sintéticos (syndet, por sus siglas en inglés) o aceites de ducha como sustitutos del jabón. Aunque no existen estudios que permitan determinar el efecto de los syndet sobre el coronavirus, los tensoactivos presentes en estos productos tienen la capacidad de inducir la disrupción lipídica de la cubierta viral, por lo tanto, serían efectivos.

- Higienización de las manos: Si no hay agua y jabón disponibles, use soluciones hidro-alcohólicas, idealmente un desinfectante para manos a base de alcohol, por lo menos al 70\%.

- El lavado de manos con jabón se recomienda antes, durante y después de la jornada laboral, cuando entre en contacto con superficies o con fluidos contaminados, antes de comer, y antes y después de ir al baño. El resto de higiene se puede realizar con soluciones hidroalcohólicas.

- El lavado de manos en la jornada laboral se debe realizar siguiendo los 5 momentos descritos por la OMS:

1) Antes del contacto con el paciente.

2) Antes de realizar una tarea aséptica.

3) Después del riesgo de exposición a líquidos corporales.
4) Después del contacto con el paciente.

5) Después del contacto con el entorno del paciente.

- Evite lavarse las manos y el rostro con agua caliente, ésto podría exacerbar síntomas como prurito y ardor.

\section{Hidratación de la piel de manos y rostro}

- Se recomienda aplicar humectantes o emolientes después de cada lavado de manos, y cuantas veces sea necesario. En aquellos pacientes con alteración de la barrera cutánea, se recomienda utilizar emolientes o humectantes libres de fragancias, colorantes y con preservantes hipoalergénicos, cuyo mayor contenido sean las ceramidas. No olvide aplicar estos productos en las orejas.

- Después del lavado del rostro, se recomienda utilizar cremas hidratantes libres de fragancias, colorantes y con preservantes hipoalergénicos.

- Humecte la piel antes del uso de gafas y mascarillas, idealmente con cremas cuyo mayor contenido sean ácidos grasos hiperoxigenados.

\section{Recomendaciones del cuidado de la piel frente al uso de elementos de protección personal (EPP):}

\section{Uso de guantes}

- Evite el uso de guantes por periodos prolongados. Se recomienda aplicar emolientes o humectantes antes y después del contacto con los guantes. En lo posible, utilizar guantes de látex, y en aquellos pacientes con factores de riesgo (antecedente de dermatitis atópica, dermatitis de contacto u otros procesos inflamatorios de la piel) usar guantes de nitrilo, ya que los guantes de vinilo son permeables. Utilice idealmente guantes sin talcos, para minimizar la formación de residuos.

- El uso de doble guante se recomienda en las situaciones especiales que lo requieran, de acuerdo a las recomendaciones de la OMS.

- No se recomienda la higiene sobre los guantes ya que podría crear un residuo que genera contaminación. Siempre se debe realizar la higiene sobre la piel.

- Cambie los guantes con frecuencia, éstos son porosos y pierden la impermeabilidad después de 20 a 30 min de uso.

- El uso continuo y prolongado de guantes, y la falta de recambio, causa oclusión y un estado de sobre hidratación de la epidermis, que es clínicamente observable como maceración y erosión, lo cual podría favorecer el desarrollo de una dermatitis de contacto y la colonización de la piel por bacterias y hongos. 


\begin{tabular}{|c|c|}
\hline Dermatosis & Características Clínicas \\
\hline Urticaria aguda & $\begin{array}{l}\text { Presencia de habones (aumento de volumen debido a edema dérmico, circunscrito, de coloración rosado pá- } \\
\text { lida, rodeado por un halo eritematoso) pruriginosos, que resuelven en un periodo de tiempo entre } 30 \text { min a } \\
24 \text { h. Las lesiones pueden aparecer en cualquier lugar de la superficie corporal, presentándose como lesiones } \\
\text { únicas o múltiples, con o sin tendencia a confluir }\end{array}$ \\
\hline Exantema maculo-papular & $\begin{array}{l}\text { Presencia de múltiples máculas eritematosas con un diámetro menor a un } 1 \mathrm{~cm} \text { asociado a pápulas sobree- } \\
\text { levadas. Puede ser tanto de morfología, extensión y distribución variable, sin embargo, la mayor parte de los } \\
\text { casos descritos en la literatura actualmente corresponde a un patrón morbiliforme, que corresponde a múl- } \\
\text { tiples máculas y pápulas de pocos milímetros confluentes dejando pequeñas áreas de piel sana en su interior }\end{array}$ \\
\hline Exantema varicela-like & $\begin{array}{l}\text { Presencia de múltiples vesículas, que en algunas ocasiones se acompañan de pústulas, sobre una base erite- } \\
\text { matosa, pruriginosas, ampliamente distribuidas, que luego de 4-6 días evolucionan a etapa costra. Es posible } \\
\text { la sobreinfección bacteriana de estas lesiones, por lo tanto, es un factor que debe ser prevenido }\end{array}$ \\
\hline Erupción petequial & $\begin{array}{l}\text { Presencia de múltiples máculas purpúricas, puntiformes, generalmente asintomáticas, debido a extravasación } \\
\text { sanguínea. Con frecuencia, en un inicio se presentan en extremidades, sin embargo, pueden expandirse a } \\
\text { todo el cuerpo. Se ha propuesto en algunas guías actuales como un signo de alarma, por lo que su hallazgo } \\
\text { debiese llevar a la realización de estudios complementarios }\end{array}$ \\
\hline Acro-isquemia aguda & $\begin{array}{l}\text { Manifestación dermatológica que contempla un amplio espectro de presentaciones clínicas. Se ha descrito la } \\
\text { presencia de máculas eritemato-violáceas en extremidades (principalmente sobre la superficie de los dedos) } \\
\text { que remedan a un eritema pernio, las cuales evolucionan a la aparición de ampollas, en algunos casos hemo- } \\
\text { rrágicas, asociado a prurito o dolor, finalizando con la formación de costras negruzcas. En algunos casos se } \\
\text { ha informado la involución completa en un periodo aproximado dos semanas, sin mayores complicaciones } \\
\text { sistémicas, no obstante, en otros casos (principalmente pacientes adultos) se describe la aparición de estas } \\
\text { lesiones en asociación con síntomas sistémicos graves e incluso shock, asociándose a gangrena de la extremi- } \\
\text { dad comprometida, incluso llevando a la muerte }\end{array}$ \\
\hline $\begin{array}{l}\text { Livedo reticularis } \\
\text { (Sin descripciones de casos } \\
\text { en pacientes pediátricos) }\end{array}$ & $\begin{array}{l}\text { Presencia de lesiones reticulares, principalmente en extremidades, de color rojo eritemato-violáceo debido a } \\
\text { una disminución en la velocidad de perfusión de las arteriolas dérmicas }\end{array}$ \\
\hline $\begin{array}{l}\text { Dermatosis agravadas en } \\
\text { contexto de COVID-19 }\end{array}$ & $\begin{array}{l}\text { Se debe tener en consideración que gran parte de las dermatosis preexistentes se pueden agravar tanto como } \\
\text { por a la infección por SARS-CoV-2, por el estrés asociado o por las diferentes medidas adoptadas sin una pro- } \\
\text { tección adecuada de la barrera cutánea. Dentro de las más frecuentes encontramos: Dermatitis atópica, der- } \\
\text { matitis seborreica, dermatitis de contacto, psoriasis, acné, vitíligo, alopecia areata, efluvio telógeno, entre otras }\end{array}$ \\
\hline
\end{tabular}

- En pacientes con erosiones por maceración se pueden usar solución salina normal o protectores cutáneos con óxido de zinc al 20\%.

- Ante la presencia de dermatitis de contacto cuya única manifestación sea eritema, será suficiente el uso de corticoides de baja potencia como hidrocortisona al 1\% combinados con cremas humectantes, dos veces al día por una semana. En caso de persistir la molestia o de mayor severidad, se recomienda consultar al dermatólogo.

\section{Uso de gafas de protección}

- Recuerde que las gafas pueden generar trauma por presión, urticaria por presión, dermatitis de contacto o empeoramiento de las enfermedades dermatológicas previas.

- Al usar gafas de protección, éstas deben cubrir la totalidad de sus ojos y la piel periocular. La protección puede incluir un protector facial que cubra completamente la frente y los lados de la cara.
- Use las gafas a su medida, sin ajustarlas de forma excesiva, e intente apoyarlas en sitios diferentes cada vez que las utilice.

- Cubra las superficies de contacto permanente (puente nasal y pómulos) con elementos que disminuyan la presión que se genera sobre la piel, tales como: apósitos de película semipermeables (una membrana delgada de poliuretano recubierta con una capa de acrílico adhesivo) o apósitos hidrocoloides (un apósito que contiene una dispersión de gelatina, pectina y carboximetilcelulosa junto con otros polímeros y adhesivos que forman un dispositivo flexible). Aunque no regulen completamente la humedad ni la temperatura, ya que son oclusivos, también se pueden utilizar apósitos de espuma (una lámina de espuma de poliuretano, hidrófoba) o apósitos finos, preferiblemente con silicona.

- Establezca y garantice períodos de descanso de duración no inferior a 15 min en los que se interrumpa la presión, cada cuatro a seis horas. 


\section{Uso de mascarilla}

- Se recomienda evitar el uso de mascarilla N95 durante más de ocho horas continuas.

- Si sufre de urticaria por presión se recomienda el uso de antihistamínicos para prevenir los episodios, además de las medidas ya mencionadas para disminuir la presión.

- La mascarilla resortada puede ocasionar presión y dolor en la piel de la región retroauricular, en tal caso, considere usar mascarilla de amarre de tiras, ajustándolo adecuadamente.

\section{Recomendaciones para el cuidado de las mucosas}

- No toque sus ojos, nariz o boca, a menos que previamente se realice higiene de manos.

- En caso de sospechar exposición a secreciones o aerosoles en la zona periocular, debe lavar con agua y jabón, cerrando fuertemente los párpados, ya que el contagio del SARS-CoV-2/COVID-19 puede ocurrir a partir del paso del virus desde la piel hacia la mucosa.

- Tenga precaución y evite el contacto directo de los ojos con soluciones hidroalcohólicas.

- No existen medicamentos en colirio que sirvan para tratar la conjuntivitis de origen viral, a diferencia de la bacteriana o la alérgica. Su uso debe ser autorizado por personal calificado, preferiblemente un oftalmólogo.

- Si es usuario de lentes de contacto, considere el cambio a gafas, con el fin de evitar el contacto y manipulación de la conjuntiva. Las gafas proporcionan una barrera adicional de protección.

- En caso de no poder omitir el uso de lentes de contacto, procure utilizar lentes de contacto desechables, de reemplazo diario. Esta recomendación no modifica el uso de gafas o máscaras protectoras.

- Tenga en cuenta que debe cumplir las indicaciones de lavado de manos de la OMS antes y después de la manipulación, inserción y extracción de los lentes, así como el protocolo de limpieza y desinfección establecido para sus lentes y el estuche donde los almacena.

- La mucosa nasal expresa el receptor de la enzima convertidora de angiotensina 2 (ECA2), por lo tanto, es una potencial puerta de entrada para el virus. El personal de la salud debe limpiarse las fosas nasales antes de iniciar su jornada laboral y previo uso de los EPP. Puede utilizar un aspirador nasal o solución salina al 0,9\%.

- Si tiene sequedad de la mucosa nasal puede usar lubricantes nasales en gel o en spray, antes y después de usar los EPP, previo lavado de manos siguiendo siempre las recomendaciones de la OMS.
- Si la mucosa nasal entra en contacto con fluidos de pacientes con infección por SARS-CoV-2/COVID-19 se deben limpiar las fosas nasales y el vestíbulo nasal con un algodón impregnado en alcohol a concentración del 70\% como mínimo.

- Los vellos nasales pueden ser un medio que facilite la adhesión viral, por lo tanto, se deben recortar.

- Idealmente, el personal de la salud no debe tener barba ni bigote, pues podrían facilitar la infección.

- Lávese los dientes en la mañana, al terminar la jornada y en la noche.

- Nunca se lave los dientes en medio del ambiente hospitalario. Aplique bálsamo labial antes de usar los EPP (prefiera productos sin saborizantes, fragancias o colorantes, y con preservantes hipoalergénicos).

\section{Otras recomendaciones a tener en cuenta}

- El efecto oclusivo de los gorros protectores puede aumentar la absorción de contactantes o medicamentos, también puede provocar prurito y foliculitis, o exacerbar la dermatitis seborreica.

- Cierre con fuerza los labios y los párpados durante el lavado de su rostro y su cabello.

- Las consecuencias de la sudoración que genera el uso continuo de los EPP se pueden prevenir tomando una ducha con agua y jabón después de abandonar las áreas de trabajo contaminadas, y aplicando posteriormente un emoliente o humectante libre de fragancias.

- En caso de hiperhidrosis axilar o en los pies, aplique lociones con cloruro de aluminio del $10 \%$ al $12 \%$ dos veces al día.

- En pliegues cutáneos aplique protectores cutáneos que contengan óxido de zinc al 20\%.

- Se recomienda el uso de uniformes de tela ligera, cómodos, y ropa interior de algodón. Se deben cambiar regularmente y cuando estén húmedos, para reducir así el efecto de oclusión.

- Para el personal de la salud que utilice trajes especiales durante largas jornadas se recomienda el uso de ropa interior y medias cómodas, que no queden ajustadas, para disminuir el riesgo de urticaria por presión.

- Mantenga el cabello corto. En caso de usarlo largo deberá llevarse recogido. En ambos casos siempre se deberá utilizar gorro.

- Al lavarse el cabello, hágalo de forma separada, inclinando la cabeza hacia atrás, evitando que el agua contaminada entre en contacto con su rostro. Hágalo con agua fría, esparciendo el champú con la yema de los dedos y no con las uñas. 
- Mantenga las uñas cortas.

- Evite el uso de esmalte. Asimismo, evite portar accesorios (reloj, pulseras, anillos, cadenas, aros) durante la atención médica, ya que el virus podría permanecer en las superficies de los mismos hasta por 12 días.

- En caso de presentar alguna lesión cutánea secundaria al uso de EPP, consulte al dermatólogo para un diagnóstico oportuno y un tratamiento adecuado.
Finalizando anexamos tabla de resumen de manifestaciones cutáneas descritas durante la enfermedad por COVID-19 en pacientes infectados (tabla 1).

\section{Conflicto de interés}

Los autores declaran no tener conflicto de intereses.

\section{Lecturas recomendadas}

1. Zhou F, Yu T, Du R, et al. Clinical course and risk factors for mortality of adult in patients with COVID-19 in Wuhan, China: a retrospective cohort study. Lancet. 2020;395(10229):1054-62. doi: 10.1016/S0140-6736(20)30566-3.

2. Organización Mundial de la Salud. Medidas de protección básicas contra el nuevo coronavirus [Internet]. 2020 [citado el 6 de abril de 2020]. Disponible en: https://www.who.int/es/emergencies/ diseases/novel-coronavirus-2019/advicefor-public.

3. Chodosh J, Holland GN, Yeh S. Important coronavirus updates for ophthalmologists [Internet]. 2020 [citado el 6 de abril de 2020]. Disponible en: https://www.aao.org/ headline/alert-important-coronaviruscontext.

4. Sociedad Colombiana de Oftalmología. Recomendaciones y estrategias para prevenir la transmisión del COVID-19 en las unidades de Oftalmología [Internet]. 2020 [citado el 6 de abril de 2020]. Disponible en: https://socoftal.com/ covid-19/
5. Wu P, Duan F, Luo C, et al. Characteristics of ocular findings of patients with coronavirus disease 2019 (COVID-19) in Hubei Province, China. JAMA Ophthalmol [Internet]. 2020 Mar 31 [citado el 10 de abril de 2020]. Disponible en: https://jamanetwork. com/journals/jamaophthalmology/ fullarticle/2764083.

6. Coronavirus Eye Safety [Internet]. American Academy of Ophthalmology. 2020 [citado el 1 de abril de 2020]. Disponible en:https://www.aao.org/ eye-health/tipsprevention/coronaviruscovid19-eye-infection-pinkeye.

7. McGoldrick M. Personal protective equipment: protecting the eyes. Home HealthcNow. 2019;37(4):234-5. doi: $10.1097 / \mathrm{NHH} .0000000000000804$.

8. Consenso colombiano de atención, diagnóstico y manejo de la infección por SARS-CoV-2/COVID-19 en establecimientos de atención de la salud. Recomendaciones basadas en consenso de expertos e informadas en la evidencia. Infectio. 2020;24(3):1-102.

9. Wang JV, Parish LC. Dermatologic manifestations of the 1918-1919 influenza pandemic. Skinmed. 2019;17:296-7.
10. Elston DM. Occupational skin disease among healthcare workers during the Coronavirus (COVID-19) epidemic. J Am Acad Dermatol. 2020;82(5):1085-1086.

11. Morey-Olivé M, Espiau M, MercadalHally M. Lera-Carballo E, García-Patos V. MANIFESTACIONES CUTÁNEAS EN CONTEXTO DEL BROTE ACTUAL DE ENFERMEDAD POR CORONAVIRUS 2019. In: Anales de Pediatría. Elsevier Doyma. 2020, April.

12. Recalcati S. Cutaneous manifestations in COVID-19: a first perspective. Journal of the European Academy of Dermatology and Venereology. 2020.

13. Joob B, Wiwanitkit V. COVID-19 can present with a rash and be mistaken for Dengue. Journal of the American Academy of Dermatology 2020;82(5):e177.

14. Singhal T. (2020). A review of coronavirus disease-2019 (COVID-19). The Indian Journal of Pediatrics, 1-6.

15. Zhang Y, Cao W, Xiao M, et al. Clinical and coagulation characteristics of 7 patients with critical COVID-2019 pneumonia and acro-ischemia. Zhonghua xue ye xue za zhi $=$ Zhonghua Xueyexue Zazhi, 41, E006-E006. 2020. 